\title{
Discussion on the application of network technology in Construction En- gineering Management
}

\author{
Zhi.Neng.Tong \\ Jiangxi Science \& Technology Normal University
}

\begin{abstract}
KEYWORD: Construction project;Project implementation;network technology
ABSTRACT: Network planning method has been widely used in engineering construction, it is in accordance with the engineering construction management requirements, especially for the project implementation process organization and management. At present, the application of project management, especially the supervision and control, tracking and adjustment of the implementation of the plan is lagging, and basically remains on the compilation of the plan.. Through the analysis of the status quo of the application of the network technology in the implementation of the process, the paper puts forward the methods and methods for the application of network planning technology.
\end{abstract}

\section{The introduction of network planning technology}

Network planning method is for project planning and control is a management technology, is a way to help people analysis work rules and scientific method for prompting the internal contradictions of the task, this method also provides a preparation and adjustment plan of complete technology. The biggest feature of the network plan is that it can provide a variety of information needed for the construction management, is conducive to strengthen the project management. It has helped managers rational organization of production, do sth in the heart, know the management emphasis should be placed where, how to shorten the time limit for a project, where mining potential. How to reduce the cost. In the project management to improve the level of application of network planning technology, will be able to further improve the level of project management.

The core of the network planning method is to provide a graphical model of the inter - logical relationship between the activities of the plan task.. Using the graphical model and the calculation method of, can see the global task plan, to analyze the rule, in order to reveal the contradiction, to seize the key, and use scientific method to adjust the plan arrangement, find out the best plan. At present, the industry developed countries in the world attach great importance to the modern management science, the network planning technology has been recognized by many countries as the current most effective management methods. The practice has proved that the application of the network planning technology organization and management production can shorten the time limit and reduce the cost.

\section{Advantages of network planning technology in construction management}

The application of network planning technology in the construction is not only a method of compiling the plan, but also a scientific method of construction management.. It can be said, at present our country network planning technique in theory and application level compared with developed countries, not much difference between. But due to historical reasons, the basis for the development of construction enterprises is weak, staff's knowledge structure is not perfect, therefore, application of network planning method in the construction management exist the situation is not optimistic, especially plan execution supervision, control and tracking adjustment aspect, less fall in real earnest, remain in the planning, of management in the implementation of the grasp is not effective, the lack of an effective way.

In building engineering, network planning technology is mainly used to preparation of construction enterprises production planning and construction schedule, and optimization, adjustment and control of the plan, to shorten the time limit for a project, improve work efficiency, reduce costs, increase the economic benefits of the.

The main advantages of network planning technology are as follows:

(1) The logical relationship between the work in the network planning technology is very strict. 
(2) The network planning technology is the effective tool for controlling the duration. The time parameter provided by the network is a dynamic plan concept, and the network planning technology can adapt to the changes of the construction conditions.

(3) The application of network planning technology can focus on the key work and can control and supervise the implementation of the plan effectively.

(4) The application of network planning technology can optimize the plan, get the best plan.

(5) The use of the network diagram, making the plan more scientific.

\section{The necessity of application of network planning technology in construction management}

Construction and general industrial production has its own characteristics, performance in:

The production space is constantly changing. As the project product fixed, and overall hard, so often in the construction process flow. The change of production space means that the construction conditions or the environment change, and the construction organization and management of the project will change with the change of the construction method and order to adapt to the new conditions.

Construction period is longer. The construction of the same engineering projects generally experienced the changes of the four seasons climate conditions, which brings great influence to the construction of the open air. In order to shorten the construction period, the project size is huge and so on the characteristic, organization, a multi-level interchange operations and parallel flow shop, the use of space to try to shorten the construction period. This method of organization construction requires the construction of different units or different types of work closely, and therefore need to develop a detailed construction organization plan, and strictly according to plan execution.

The individuality of project. Different engineering projects will bring about the changes of natural and technological economic environment due to the different uses and geographical locations.. Therefore, the different engineering projects have different construction organization characteristics, and it is impossible to carry out mass production.

Complexity of engineering projects. Along with the progress of science and technology, the scale and complexity of engineering projects continue to increase.. Because of the complexity of the project, it is necessary to implement the specialization, so it must strengthen the coordination of various types of projects in the project construction. The project manager only uses the engineering project plan, can he emphasized the progress, the cost, the quality communicated to the engineering technical personnel.

The construction of engineering projects has the characteristics of the single production, the changeable environment and the strict and close coordination, which decides the complexity of the construction organization and management.. Only in the construction management application network plan technology, a project as a whole to consider, in accordance with certain procedures to arrange, and through the network plan itself unique feedback, adjustment and improvement of construction management, can the construction can fully meet the quality, saving and fast. The construction practice proves that the application of network planning technology organization and management can shorten the construction period and reduce the cost.

\section{The network plan technology in the construction management problems and reasons}

Network planning method is not only a method of compiling a plan, but also a scientific method of construction management, but its application in construction management in China is not optimistic.

\section{Problems}

Application penetration is not high. The quality of the existing construction enterprises in China is different, and the development is also very uneven.. Construction enterprises directly under the central and provincial levels, higher management level, a higher proportion of the surface the application of network planning and construction management; municipal and county level and below the construction enterprises, technical management level is relatively poor, application of network planning organization and management of the construction area ratio is low. 
Application management level is low. The application of the majority of the construction enterprise network planning technology is only on the compilation plan, and lacks the effective management method for the supervision and control and the plan adjustment in the plan execution.

Application depth is not enough. Preparation of construction network plan is often only reflect the whole project in between each unit of work of mutual restriction and mutual dependence relationship, not according to the construction method to determine the relationship between the unit of work in the preparation of depth is not enough, not to mention the optimization of network plan.

\section{Analysis}

Is caused by the network planning technology in construction management in our country application is not ideal in many aspects, the influence of the external environment, but also control the construction quality of the enterprise itself is not high, is the result of many factors.

\section{The impact of the external environment}

The influence of the external environment including the engineering design, the time limit for the determination of the administrative interference, the progress of the project is not closely linked with the network plan, engineering, etc.

Engineering design change frequently to the establishment and adjustment of the network plan brought great difficulties, the construction company overwhelmed, unable to use the network project implementation and construction management; some project construction period to determine violations of the laws of science. The date of completion of the project again ahead of the enterprise according to the network planning to organization and management; project payment is not timely and the payment is not closely integrated with the network planning, objectively weakened the responsibility of enterprise applications, network planning.

\section{Enterprise own quality control}

(1) The obstruction of the traditional way of work. The traditional construction management uses the manual management and a lot of work is to rely on the experience to complete, the enterprise has the necessity to realize the network plan management to realize the insufficiency. Many construction workers refused the network plan because it is not used to network planning management, there is no traditional way of management as handy.

(2) Extensive construction management. Construction management in field follow checking there is no system, optional sex is big, schedule data collection is not comprehensive, not complete, progress data consolidation, statistics, processing and analysis ability is poor, no person in charge of the other.

(3) Lack of high quality management personnel. At present most of the construction enterprise management personnel and engineering and technical personnel, they often only pay attention to the research on construction technology, management schedule dependent on the Gantt chart management, master the knowledge of network plan technology lack of systematic and comprehensive.

\section{Improve the application level of network planning technology in construction management}

Based on the above analysis, the construction enterprises to improve the application level of network planning technique, in addition to grab from fountainhead, formulate effective measures to improve the enthusiasm of enterprise applications, network planning technology, more important is enterprise itself from improve the market competitiveness, through the full implementation of the network planning to promote enterprise management quality and level.

\section{Standard building management system, for the application of network technology to provide a good environment}

Strengthen engineering design management, reasonably determine the construction period. Through the establishment of a system, the promotion of engineering design and the time limit for a project is scientific and reasonable, and the subjective determination of the frequent change and the construction period of the design is forbidden.

Improve the project supervision system. In the same time, the supervision of engineering supervision is to supervise the progress of the project, and guarantee the consistency and coordination of the progress control and quality control and investment control. 
To establish the mechanism of the project payment strictly according to the network progress plan. The project payment and the network schedule plan closely, not only enhances the enterprise application network plan to carry on the construction management consciousness, simultaneously also urges the network plan to compile more feasible.

\section{To meet the needs of scientific management, strengthen personnel training and Application Research}

To develop the relevant regulations, strengthen the standardization work. According to the situation and features of the industry, the network planning and management regulations are formulated, and unified drawing, term and network model are formulated, which is convenient for popularization and application.

Multi route training talents. Industry associations and the competent administrative departments shall organize write practical training materials, network planning technology and computer application training class held, on the construction of enterprise technical leadership and construction management personnel training, learning and mastering the network plan technology; colleges and universities to increase the modern management technology courses, to enable students to after graduation, which can meet the needs of modern management.

\section{To raise awareness, pay attention to actual effect, to improve the management level of the en- terprise}

The construction enterprise is the main body of the application of network planning technology, the construction of the comprehensive implementation of the network plan management is the key to improve the management level of our country construction enterprise.

The concept of change, fully understand the importance of network planning technology. The biggest feature of network planning method is that it can provide a variety of information required for the construction management, and it can help the management to organize the production reasonably.. Application of network planning in the construction management is bound to get the full effect of the province, and improve the construction management level.

Adopt easy acceptance control form. Gantt chart is engineering and technical personnel most familiar forms of control, is intuitive and easy to understand, easy draw, required less time, the characteristics of low cost, but the drawback is cannot reflect the interdependence and mutual restriction relationship between the work and it is difficult to control in large and medium-sized project schedule. After the network plan technology to compile and adjust the schedule, converted into a form of Gantt chart to implement, such practices not only network as the tightness, and both cross the road map is simple and easy to understand the advantages, reduce resistance in the implementation of network planning.

Management and technical personnel closely integrated. The preparation and implementation of network planning is established based on the known construction methods based, construction management personnel in addition to the familiar network planning method outside, should also understand the process and organization of the work. According to the nature and characteristics of the network planning technique, not an applied network planning method can arbitrary shortening the duration of the project, it only to management personnel provide in what reasonable acceleration and time limit for a project and cost relationship information. Therefore, the management to develop scientific and reasonable progress control plan must be closely integrated with engineering and technical personnel.

The regular inspection of network plan is the most effective method to supervise the plan.. The necessary amendment is the measure to guarantee the progress of the engineering network.. During a certain period of execution, a relatively stable plan is required, which is the basis of network planning management.. Regular and timely records, check the schedule implementation, not only can adjust the network for the, but also help in the data accumulation, engineering analysis and summary, and constantly improve the planning level and network plan management level.

Network planning technology is a scientific construction management thought and methods, its application is not only a technical problem, is also involved in the project management system and project related units, individuals and other aspects of the factors. Through the full implementation of the network technology has a very important significance for provided the management level of the enterprise, shorten the construction period, improve labor productivity and reduce the cost and improve the construction enterprise network technology application level, in addition to as soon as 
possible to standardize the construction management system, and to develop effective measures to improve the enthusiasm of the enterprise application of network technology, more important is to enterprises to improve their own competitiveness in the market.

\section{Reference}

[1] Yuan Ziren Network construction management [M] China Building Industry Press, 1987

[2] China Architectural Society Building and overall management research associationChina network program technology [M] Earthquake Press, 1993

[3] Zheng Mei Construction project management [M] China Planning Press, 2004.6

[4] Wei Daojun Eengineering project management [M] Wuhan University press, 2004.4 